\title{
COSMOGONÍA Y COSMOVISIÓN EN LA RACIONALIDAD Y EL PENSAMIENTO COCAMA-COCAMILLA
}

\section{COSMOGONY AND WORLDVIEW IN THE RATIONALITY AND COCAMA-COCAMILLA THOUGHT}

\author{
Ferdinand Hagiwara Grández ${ }^{1}$
}

\begin{abstract}
RESUMEN
Las nuevas tendencias interculturales buscan recuperar los conocimientos de los pueblos ancestrales olvidados por mucho tiempo o minimizados hasta la nihilización por tendencias etnocentristas de origen europeo. Determinar si los pueblos conquistados o colonizados de América han tenido formas racionales propias, (entiéndase filosofías), siempre ha sido materia de discusión. El encuentro entre europeos y americanos significó un choque cultural entre dos maneras de entender el mundo, dos racionalidades distintas, que ubicaban a una encima de la otra por el solo hecho de implicar una relación de poder: vencedores y vencidos; se ponían a los vencidos al borde de la barbarie y la incivilización, y a los vencedores en el pináculo de la cultura y la civilidad, que a la larga han llevado a interpretaciones univocas de lo que es el ideal de hombre (el europeo es el prototipo por excelencia), con la consiguiente minimización del hombre autóctono americano. Esto ha llevado a un reduccionismo cultural, pues al negar otros "tipos de hombre", ni siquiera se intentó descubrirlos. En todo caso, el presente artículo intenta una nueva visión de esta problemática en el mundo amazónico, una nueva mirada a la luz del pensamiento divergente y un nuevo paradigma de la complejidad en una etnia representativa de este mundo: los Cocama-Cocamilla, otrora dominadores del río y la floresta.
\end{abstract}

\section{PALABRAS CLAVE:}

Interculturalidad, pensamiento divergente, paradigma de la complejidad, Amazonía.

\begin{abstract}
The new intercultural trends seek to recover knowledge of ancestral peoples long forgotten or minimized until nihilization by ethnocentric drift of European origin. To determine whether conquered or colonized peoples of America have had own rational ways (to wit philosophies) has always been a topic of discussion. The encounter between Europeans and Americans entailed a culture shock between two ways of understanding the world, two different rationalities, which put one over the other by the mere fact of implying a power relationship: winners and losers; the latter were placed on the edge of barbarism and the former at the pinnacle of culture and civility, which in the long run has led to unambiguous interpretations of what is the ideal of man (the european is the prototype par excellence), with the subsequent minimization of the native American man. This has led to a cultural reductionism, since it denies others "types of man", not even an attempt was made to discover them. In any case, this article attempts a new approach of this problem in the amazonian world, a new look in the light of divergent thinking and a new paradigm of complexity in a representative ethnicity of this world: The Cocama-Cocamilla, once rulers of the river and the forest.
\end{abstract}

\section{KEYWORDS:}

Interculturality, divergent thinking, paradigm of complexity, Amazon, Cocama-Cocamilla.

* Docente de la Universidad Nacional de la Amazonía Peruana: ferdinandluis@hotmail.com 


\section{INTRODUCCIÓN}

Cuando los españoles llegaron a tierras americanas encontraron un mundo totalmente diferente al suyo, siéndoles difícil descifrar y entender este mundo, manifestado en otro tipo de universo mental, sobretodo porque la mentalidad occidental manejaba otras categorías que diferían en los usos y costumbres de estos pueblos recién conocidos.

Para el español era mejor y más cómodo manejar el criterio etnocéntrico, por el cual consideraba su cultura superior a las encontradas y como tal tenía que imponerla y enseñarla hasta lograr la asimilación de sus formas culturales por "los indígenas".

Este proceso duró desde los primeros contactos, en el siglo XV hasta aproximadamente mediados del siglo XIX, en donde la Antropología desde los aportes de la escuela inglesa y francesa, empezó a valorar las formas culturales diferentes; es decir, pertenecientes a otros pueblos que no eran de origen europeo.

Los antropólogos ingleses y franceses se lanzaron frenéticamente a la búsqueda de la "otredad", por lo cual, en un primer momento la etnografía (investigación de etnias en una convivencia directa) fue el mejor instrumento para documentar aspectos antes desconocidos.

En este contexto, las etnias amazónicas, también han representado un reto en el conjunto de culturas existentes, ya que todas ellas manejan lenguas distintas al castellano, y como tal, también racionalidades o formas de entender el mundo muy diferente a la forma occidental.
Una de estas racionalidades diferentes pertenece a la etnia cocama, la cual encierra una riqueza cultural extraordinaria, por representar una manera de concebir el mundo, un ordenamiento y jerarquización, que los hacen diferentes de otros pueblos en la floresta amazónica.

En ese sentido, queremos descifrar ese misterio subyacente en el universo mental de los cocamas que conservan mayormente, toda esa línea de pensamiento heredadas desde sus antepasados y que aportará nuevas luces acerca de una cultura que ha sido básica en el mestizaje de poblaciones amazónicas importantes como son Iquitos, Nauta, Requena entre otras.

Esta cercanía física, muchas veces, se ha convertido en una lejanía cultural, en el sentido que los pobladores de las ciudades amazónicas mencionadas, no tienen una comprensión exacta acerca de las fuentes de aquellos elementos culturales y de la racionalidad que las constituyeron.

\section{DATOS ETNOGRÁFICOS DE LOS COCAMA}

En la base de datos del AIDESEP (Asociación Interétnica de desarrollo de la Selva Peruana) encontramos que los Cocama-Cocamilla se autodenominan Kukama-Kukamiria y que cuentan con una población aproximada de 40,000 habitantes, según información proyectada, distribuidas en 51 comunidades nativas en la región Loreto en los ríos Huallaga, Bajo Marañón, Bajo y Alto Ucayali, Amazonas y Bajo Nanay, con un remanente en Colombia, aproximadamente de 300 personas.

Aunque la tendencia actual es considerar a estos pueblos como si 
fuesen uno, las crónicas coloniales se refieren a ellos de manera específica. Hablan de la nación Cocama o la Gran Cocama, llamada así por su fama de haber tenido mucha gente y por el temor que inspiraba entre las etnias vecinas del Ucayali, cuando recorrían los ríos en armadas de cuarenta y cincuenta canoas.

A los Cocamilla (Kukamiria), etnia afín y prima hermana de la Cocama, las crónicas los nombran como la Pequeña Cocama o también como los guallagas, por estar sus asentamientos a orillas de este río.

Ellos compartían con sus vecinos los Jeberos el rasgo común del vestido masculino, consistente en un corto poncho, abierto a los costados, que les llegaba hasta la cintura.

El padre Lucas Espinosa indica dos probables orígenes de la palabra Cocama (kukama), dependiendo de las raíces que se tomen para explicar el vocablo; podría significar 'gente de fuerza' o 'gente de allá'. En el caso de la palabra Cocamilla (kukamiria) señala que su significado sería 'cocama de corazón' o 'cocama legítimo'.

\section{REFERENCIAS HISTÓRICAS}

Los Cocama son mencionados por primera vez en la crónica de la expedición de Juan Salinas de Loyola, en 1557, que fue además el primer europeo en navegar el río Ucayali.

El espectáculo debe haber sido impresionante: en la crónica se mencionan pueblos de entre 200 y 400 casas cada uno, que se extendían a lo largo de más de $300 \mathrm{~km}$. en las márgenes del río. El nombre de Gran Cocama quedaba así justificado.

Un siglo más tarde, los jesuitas iniciaron su trabajo de reducir a la población en centros misionales, con la finalidad de evangelizarlos y de aprovechar su fuerza laboral en las encomiendas y en la expansión de su propia obra religiosa.

A partir de entonces se presentan en la zona una serie de epidemias debido al hacinamiento poblacional que ocasionan muertes masivas entre los indígenas, lo que genera no pocas rebeliones contra los misioneros, a quienes dan muerte, retornando nuevamente a su hábitat natural: el bosque.

En los siglos posteriores (fines del XIX y principios del XX), los auges económicos del barbasco (Lonchocarpus) y el caucho (Castilloa ulei) los barones del caucho Arana y Fitzcarrald, reclutaron mano de obra cocama, haciéndoles partícipes de la más cruel explotación humana en esta actividad económica de la extracción del caucho, que sirvió solo para beneficiar a estos barones inescrupulosos.

De esta manera, muchos migraron al Brasil para trabajar en haciendas y otros se convirtieron en Cocamas andariegos y se expandieron por toda la Amazonía peruana, sirviendo como guías a exploradores y turistas, por el gran conocimiento de la zona que adquirieron producto de estas peregrinaciones. Hoy encontramos, por esta razón, descendientes de cocamas en lugares tan distantes entre sí como Pucallpa (San Pablo de Tushmo), los alrededores de Iquitos (poblados de Santo Tomás, Rumo Cocha y Santa Clara) y el río Putumayo, frontera con Colombia. También están en Nauta, ciudad que fue fundada hace más de 150 años por un cocama conocido como el cacique Pacaya.

\section{SITUACIÓN ACTUAL}

El adoctrinamiento religioso, los matrimonios con gente venida de fuera, 
su dispersión espacial y su inserción en el mundo urbano han producido una serie de cambios en este pueblo. Uno de ellos es la paulatina pérdida de su lengua en sus descendientes. Esto último, sin embargo, ha comenzado a cambiar en los últimos años, a partir de la vinculación de la gente con el movimiento indígena nacional liderado por AIDESEP, quienes desarrollan proyectos de recuperación de la lengua y la cultura.

Los cocamas han constituido dos federaciones que actúan en las cuencas del Pacaya y del Samiria. Las comunidades enfrentan serios problemas en la actualidad por estar asentadas en una zona declarada como reserva nacional y por la negativa del Ministerio de Agricultura a reconocerles el derecho a la titulación de sus tierras, tal como lo establece el Código del Medio Ambiente.

Al respecto, en la misma información del AIDESEP se señalan algunos puntos de vista de pobladores cocamas quienes manifiestan: El bosque es nuestro mercado y nuestra vida, en el bosque están los mamíferos, peces, aves y tortugas que sirven de alimento a la gente; y los pequeños animales (larvas, cangrejos, caracoles), frutos y demás productos vegetales que recolectan para comer o construir sus viviendas y utensilios domésticos. En el bosque habitan también los seres de la naturaleza, dueños y guardianes del monte a quienes los indígenas deben pedir permiso cuando quieren tomar alguno de los animales o plantas que protegen.

Con ellos la gente establece relaciones de reciprocidad similares a las que rigen su vinculación con las demás personas.

Este aspecto de los espíritus del bosque y de las relaciones de reciprocidad que se establecen con ellos, es muy importante en la cosmovisión cocama y tendría relación con el principio de relacionalidad que manifiesta Estermann (1998: 114) donde lo presenta como el rasgo fundamental de la racionalidad andina. Este rasgo nos llevaría a considerar paradigmas actuales como el de la Complejidad que presentan visiones holísticas e integrales de lo que es el hombre. Al respecto Romero (2003) señala que el Paradigma de la Complejidad aglutina a científicos de diversos campos de conocimiento que insisten en la conveniencia de adoptar nuevos modelos teóricos, metodológicos y, por ende, una nueva epistemología, que permita a la comunidad científica elaborar teorías más ajustadas de la realidad que posibilite, al mismo tiempo, diseñar y poner en prácticas modelos de intervención -social, sanitaria, educativa, política, económica, ambiental, cultural, etc. - más eficaces que ayuden a pilotar y regular las acciones individuales y colectivas. Subyace en esta actitud reformista un firme intento de reformar la racionalidad sobre la que la ciencia y la tecnología se han venido apoyando. Esta actitud reformista afecta indistintamente tanto a las ciencias empírico-naturales como a las ciencias sociales y humanas y, en consecuencia, incide asimismo en las Ciencias de la Educación.

\section{ASPECTOS PRINCIPALES DE LA COSMOGONÍA Y COSMOVISIÓN COCAMA}

(Rivas, 2000: 31) manifiesta que para realizar sus actividades los CocamaCocamillas mantienen una estrecha interrelación con su medio ambiente y con el cosmos. Las categorías astronómicas temporales son las siguientes: el sol (kuarachi), la luna (yatse), las estrellas (ts $+\mathrm{tsu})$.

Asimismo, entre las constelaciones observan a las Pléyades (Wata ts+tsu), 
Orión (Awa tsu+ma), Antares de Escorpión (Yakari tsaiwa). Sin embargo, los Cocama-Cocamilla expresan en una sola categoría (kuarachi) al orbe celestial, al cielo y al día.

Además tienen expresiones para referirse a los diferentes momentos del ciclo diurno: Kanatari ñutsu, va a amanecer (3 o 4 a.m.), ini kanata, ya ha amanecido (5:30 a 6 a.m.), kuarachi uchimari utsu ó ai kuarachi uchimari, ya sale el sol (entre las 6 y 7 a.m.), Wati kuarachi ó ay kuarachi iwati Ya está arriba el sol (7 a.m.) es cuando el sol aparece por encima de la cobertura de los árboles, Ipankatukuari kuarachi utsu (más o menos a las 10 a.m.), Ipankatuka kuarachi o ay kuarachi ipamatuka (medio día), Ay kuarachi kakurupika (ya va a ser tarde), kuarachi akiari yutsu (ya se oculta el sol=ocaso), Ay kuarachi aki (ya ha entrado el sol), + $\mathrm{p}+\mathrm{tsa} \mathrm{m}+\mathrm{r}+\mathrm{ti}$ ini (media noche, todo está en silencio, no se escucha ningún ruido). En general, la noche se denomina $+p+$ tsa.

Continúa Rivas señalando, que para los Cocama-Cocamilla la luna, yatse y sus distintas fases tiene una influencia muy grande para la realización de las actividades, en especial de la agricultura. No en vano el proceso de crecimiento de la luna es percibido como un fruto en vía de madurar. Este astro es también importante para la computación del tiempo. Ellos tienen cinco vocablos para percibir a la luna en sus diferentes fases: $+\mathrm{k}+$ ran Yatse, +wati Yatse, Manawari Yatse, kaku-rupe Yatse y ukaima Yatse.

El mundo empieza al nacer Kémarin, el primer hombre kukama, hijo de una gran mujer boa y de Kémari, el dios kukama, una paloma que se convirtió en ángel.

Los primeros tsumi, chamanes ayahuasqueros conocen por medio de sus visiones que hay cinco espacios o soles, que llamamos así porque el sol atraviesa todo.

En el Wepe Kuarachi, primer sol, debajo del agua viven los kuarara con sus gorras que son rayas (pez grande de la selva) y sus casas de pura tierra. También un inmenso muiwatsu (boa) que bota burbujas al mundo de los peces.

Los kuarara le piden al tigre de agua que sujete al muiwatsu para que no salga de la cocha porque si sale habrá grandes remolinos.

En el Wepe Mukuika, segundo sol, viven los peces, lagartos, bufeos (delfín de río), el paiche y las boas pequeñas. La dueña del agua es la Ipira Mama con sus largos cabellos. Ella decide que crezca o merme el agua.

En el Mutsapirka, tercer sol, vive el pueblo cocama con sus plantas, animales, seres naturales, curanderos y la gente que ha muerto.

Cuando queremos sembrar, pescar o ir de cacería se les pide a los dueños o espíritus que viven en el monte, en el agua, en la tierra, en el árbol y en otros lugares para que los animales caigan en las trampas.

En el Irakua, cuarto sol, viven las almas y se relacionan con el médico ayahuasquero. En las casas que se encuentran entre flores, estrellas y pájaros, sobre la cumbrera, viven las almas de los muertos buenos. Los muertos malos son quemados y sus cenizas forman las nubes del cielo.

En el Pichka, quinto sol, vive Dios y también está Kémari, el dios kukama, una paloma convertida en ángel. Más abajito, se encuentran los cerros y, 
elevado en medio de eso, vive el cóndor mama, el jefe de todas las aves de la tierra.

\section{CELEBRACIONES Y FIESTAS}

Los cocama influidos tal vez por la sociedad actual, han dejado de realizar algunas de sus antiguas celebraciones, como por ejemplo, la de la pubertad, en la que encerraban a las muchachas en una casa apartada cuando tenían su primera menstruación, con el cuerpo pintado y adornado con plumas multicolores de diversas aves. Este aspecto quizás se deba a que en la sociedad actual el paso de la niña para ser mujer se valora como un proceso que tiene una etapa específica: la adolescencia y que en el caso de la cultura cocama se celebraba en un tiempo determinado donde no existe tal prolongado proceso, la niña cuando menstrúa ya se convierte en mujer, porque está demostrando su capacidad reproductiva.

La ceremonia del corte de pelo sí es festejada aún. Al niño se le dejan crecer los cabellos desde su nacimiento. Al cumplir dos años, se le atan mechones de pelo con cintas de diversos colores, cada uno de los cuales le corresponde a un distinto padrino que tiene que pagar una contribución por cortarlo. El padrino principal paga una suma mayor. La cantidad reunida es entregada a los padres del niño para que atiendan sus necesidades. Luego, todos los asistentes danzan y brindan con chicha de yuca (masato) por los padres y por el niño. Estas celebraciones marcarían el destete de la madre y la capacidad del infante de dejar los brazos maternos y poder movilizarse por sí mismo, pues "ya sabe caminar", en zonas andinas también se pueden observar este tipo de celebraciones y tendrían la misma connotación que en los cocamas.
Después de la Conquista, los Cocama han sido muy influidos por el cristianismo, de allí que muchas de sus fiestas se refieran a eventos propios de esta tradición religiosa. Por ejemplo, Bajada de Reyes (6 de enero), Semana Santa, Corpus Cristi, Todos los Santos y Navidad. Inclusive, cuando hemos realizado visitas a comunidades nativas como la de Independencia (Río Amazonas 08 y 09 de Diciembre 2012), observamos que los más jóvenes presentan en sus creencias cosmogónicas relatos llenos de sincretismo, donde podemos deducir la fuerte influencia del cristianismo en los elementos tradicionales o autóctonos y que ellos lo viven como algo monolítico sin siquiera sospechar de la diferencia de sus orígenes.

\section{RELACIÓN ENTRE LAS ARTES Y LA COSMOGONÍA}

Los cocamas, así como muchas etnias amazónicas, manifiestan a través de su arte aspectos relacionados con su cosmogonía. Al respecto, Wuffarden (2010), señala que Naturaleza y Artificio no han sido nunca términos opuestos entre los pueblos tradicionales de la Amazonía. Sus bellos artefactos de uso cotidiano o sus objetos suntuarios y rituales nos hablan con elocuencia de una tenaz relación armónica con el hábitat. A diferencia de las culturas nativas de la costa y la sierra, violentamente interrumpidas por la conquista española, estos grupos humanos constituyen un ejemplo vivo de permanencia y continuidad en el tiempo que ayudará a comprender desde el presente las funciones y los códigos simbólicos que dieron sentido a las artes visuales en el Perú prehispánico.

Lejos del misterioso mutismo que envuelve a las piezas arqueológicas, estamos ante objetos en pleno uso. 
Testimonios de vida que parecen haberse mantenido virtualmente inalterados durante siglos. El peso de la tradición explicaría, así, la habilidad técnica del artesano y la eficacia de su simbolismo, basada en la reiteración de patrones formales compartidos por la comunidad. Al igual que en los ritos, la repetición del trazo y el diseño vuelve a instaurar en cada pieza el ciclo inexorable de fuerzas vitales y su correlato sagrado.

Resulta imposible desligar aquí la forma de la función y ambas de su sentido trascendente. De este modo se entenderá la importancia invariablemente concedida a los géneros relacionados con el adorno personal. Incluso el escaso mobiliario selvático, casi siempre circunscrito al uso individual, podría percibirse como una prolongación del cuerpo humano. Si bien no se trata de obras destinadas a la pura contemplación, en ningún caso se reducen al simple ornamento. Ellas contienen precisos mensajes de distinción o de rango social dentro del propio grupo o frente a las demás etnias.

Entre todos aquellos géneros, tal vez el arte plumario continúe siendo el más llamativo a ojos del espectador occidental. No es de extrañar que la búsqueda de aves exóticas y plumajes coloridos haya sido una de las razones que, en tiempos de los últimos incas, impulsaron a la conquista -parcial y precaria- de estas tierras.

De hecho, la nobleza cusqueña solía ostentar la posesión de guacamayos como emblemas de riqueza y poder. Al llegar los primeros europeos, el deslumbrante despliegue de ajuares plumarios quedaría grabado en su memoria y sería rápidamente incorporado a las representaciones alegóricas del continente americano. Muchos de los actuales tocados de plumas reciben todavía el nombre de "coronas" por comodidad semántica, aunque no siempre sean distintivos de autoridad.

Entre los pueblos achuar, awajun, wampis y kandozi, por ejemplo, el uso de tales atuendos corresponde a momentos festivos o a las raras ocasiones en que se visita a los vecinos. De acuerdo con la colocación o el color de las plumas, el usuario busca ejercer el mismo atractivo que el de las aves durante el cortejo nupcial o disfrutar de sus cualidades reales $\mathrm{O}$ atribuidas. A veces, entre los ashaninka y los nomatsiguenga, ejemplares disecados a manera de pendientes añaden un componente "hiper-realista" llamado a distinguir las virtudes del buen cazador.

Aquellas concepciones "animistas" se manifiestan con mayor claridad en el uso extendido de las máscaras que entremezclan lo ritual con lo festivo. Sea de carácter humano, animal o totémico, la máscara trasmite transitoriamente las cualidades de lo representado. En la fiesta bora del pijuayo, por ejemplo, el disfraz de fibras vegetales y la máscara se integran para encubrir por completo el cuerpo del figurante. El atuendo culmina en una talla con figura de animal, para recordar así la importancia de ese fruto como soporte del ciclo vital en la zona. Estas piezas de madera policromada conjugan armoniosamente la estilización con algunos detalles naturalistas que dan cuenta de una capacidad de observación decantada con el paso del tiempo.

Otras formas escultóricas están igualmente asociadas con la música y la danza. Aparte de los manguarés o tambores de señales de los awajun, boras y huitotos, los bastones rítmicos aparecen con cierta frecuencia. En contraste con sus similares andinos, dotados con dijes o sonajas metálicos, 
aquí los elementos sonoros se obtienen de semillas o frutos secos.

Por lo general, la empuñadura o remate del bastón lo constituye una cabeza de animal relacionada en cada caso con el espíritu de la celebración. Hallamos un buen ejemplo de ello en la fiesta bora de la garza.

Todavía sabemos poco de las esculturas antropomorfas en madera. Algunas veces representan a los difuntos, y tal vez hayan cumplido funciones de recordatorio fúnebre entre los grupos familiares. Este culto a los antepasados recurre, en algunas culturas, a la adición de cabellos naturales o vestimentas confeccionadas con cortezas o fibras vegetales, cuyo "realismo" se complementa con la aplicación de pinturas faciales.

Pudieron tener un origen similar las conocidas figuras de madera de balsa trabajadas por los shipibo, que optan por el diseño geometrizante como única decoración.

La línea y el color fluyen con gran seguridad sobre diversas superficies, desde recipientes cerámicos hasta prendas de vestir. Es significativo que algunos ropajes tradicionales como la cushma, a modo de segunda piel, reciban los mismos diseños geométricos que se aplican sobre el propio cuerpo, utilizado como superficie pictórica.

Quizá las cortezas vegetales con representaciones míticas de los tikuna sean lo más cercano al concepto pictórico bidimensional, inexistente en las tradiciones nativas.

Desde la década pasada, Pablo Amaringo, fundador de la escuela Usko Ayar en Pucallpa, partió de sus experiencias derivadas del consumo ritual de la ayahuasca en busca de ese peculiar estado exacerbado de la conciencia que le permitiese estructurar sobre el plano sus concepciones del universo.

Es sólo en estos últimos años, al contacto con la demanda de los medios urbanos y con la creación de otras escuelas locales, que el surgimiento de una cultura amazónica parece tomar cuerpo.

No obstante, las "cosmovisiones" aquí incluidas son obra de conocedores de su medio, en algunos casos chamanes o jefes, pero en su mayoría ajenos al oficio pictórico. De algún modo, sus trabajos nos recuerdan los esfuerzos gráficos de Felipe Guamán Poma de Ayala y de Juan Santa Cruz Pachacuti, a inicios de la Colonia, para comunicar a los "otros" la visión indígena del mundo.

Continúa Wufarden señalando que al igual que aquellos primeros cronistas, los actuales "especialistas" de la Amazonía recurren a la representación estratificada en diversos niveles para traducir el "arriba" y el "abajo" simbólicos.

En su caso, la certera intuición en el uso del color contribuye de manera crucial a evidenciar la envolvente naturaleza boscosa y acuática de la selva.

A partir de estas reveladoras imágenes, se empieza a situar en contexto, la memoria cultural de los pueblos amazónicos y tiende puentes hacia su impostergable comprensión

\section{UNA MANERA RELIGIOSA DE MIRAR EL MUNDO}

Santos Granero (2010) del Smithsonian Tropical Research Institute, manifiesta que, en el caso de las 
cosmovisiones indígenas amazónicas, no sólo se plantea la existencia de una diversidad de mundos, cada uno con sus propias topografías, habitantes y leyes, sino la existencia de una diversidad de esferas al interior del mundo en que vivimos.

En efecto, un rasgo común a estas cosmovisiones es su concepción animista del universo, la cual postula que todo lo material, sea objeto o sujeto, tiene una contraparte espiritual.

En el caso de los objetos, los fenómenos que llamamos "naturales", y los animales, su dimensión espiritual es concebida como una esencia primordial: la forma primera y verdadera que éstos tenían en el origen de los tiempos, antes de adquirir su apariencia actual. Estas esencias, que por lo general tienen forma humana, son parte integrante de las cosas, fenómenos y animales, pero suelen desprenderse y vagar por esta tierra. Además, existen en el mundo una serie de seres incorpóreos: divinidades, demonios, espíritus benévolos y malévolos que pueden adquirir una apariencia material y hacerse visibles, pero cuya esencia es espiritual e invisible.

Para los indígenas amazónicos la realidad material es una máscara, un disfraz, que oculta la "verdadera" realidad. No por ello, sin embargo, es una realidad "menos real". Tanto la apariencia material como la esencia espiritual son consideradas reales, pero mientras que la apariencia no es más que un "envoltorio" pasivo, a la esencia se le atribuyen poderes extraordinarios.

Los mundos invisibles, así como los seres espirituales y las esencias primordiales que los habitan, son depositarios de conocimientos y fuerzas místicas que son indispensables para el bienestar de los humanos y el buen funcionamiento de su sociedad. Por ello, un elemento central en la experiencia religiosa de los indígenas amazónicos, tanto en el ámbito personal como en el colectivo, es llegar a conocer la dimensión normalmente invisible de la realidad.

De acuerdo a la religiosidad indígena, el acceso a estos mundos invisibles sólo se puede lograr a través de una de las múltiples almas o esencias que componen la dimensión espiritual del ser humano. Esto se consigue a través de los sueños, cuando el alma se desprende del cuerpo y vaga por este y otros mundos; a través de la ingestión de sustancias sicotrópicas o alucinógenas, tales como la ayahuasca, la datura o el jugo concentrado de tabaco, las cuales se cree inducen al alma a desprenderse del cuerpo y a emprender viajes astrales; o a través de una serie de prácticas ascéticas o de mortificación del cuerpo, tales como vigilias y ayunos prolongados, que tienen igual efecto.

Por medio de los sueños, todos: hombres, mujeres, niños y niñas, pueden experimentar contacto con los mundos invisibles, y a través de ello obtener conocimientos relevantes para su vida productiva y afectiva. Pero sólo los especialistas, tras un riguroso entrenamiento, pueden viajar a estos mundos sagrados y obtener de sus habitantes conocimientos y poderes que les permitirán más adelante impartir salud o enfermedad, vida o muerte, abundancia o destrucción.

En general los pueblos indígenas consideran que el bienestar de los individuos y las colectividades depende de que se mantenga una relación armoniosa entre el mundo visible de los humanos y los mundos invisibles 
de las divinidades, los espíritus y las esencias primordiales. La caza excesiva o el desperdicio de lo cazado pueden enojar al espíritu tutelar de la caza o a la esencia primordial de la especie animal cazada en demasía. El despilfarro de comida puede encolerizar a las esencias primordiales de las plantas o a los espíritus guardianes de las chacras.

Los seres así agraviados pueden vengarse de los infractores ocultando a los animales o haciendo que las chacras no produzcan. En dichos casos, la armonía y el equilibrio entre los diversos ámbitos del cosmos sólo puede ser restaurada a través de las prácticas ceremoniales de los especialistas religiosos: shamanes, sacerdotes o profetas.

Continúa Santos señalando que es asimismo, a través de sus operaciones rituales que estos especialistas protegen a sus comunidades de las acciones de los espíritus maléficos que pueblan los diversos espacios del cosmos.

La obtención de conocimientos y poderes de los seres sagrados son fundamentales para la supervivencia humana. No menos importante, sin embargo, es el papel que estos seres juegan como fuente de capacidades creativas e inspiración estética. Muchos de los diseños utilizados en la ornamentación de textiles, cerámica, chaquiras y cestería son aprendidos en sueños o revelados por seres sagrados durante la realización de viajes astrales a los lejanos mundos espirituales. Lo mismo es cierto de gran parte de la música, los cantos y las danzas.

En vez de establecer rígidas fronteras entre naturaleza y sociedad, lo humano y lo animal, lo sagrado y lo profano, tal como es común en las sociedades de tradición occidental, las cosmovisiones indígenas se fundamentan en la multiplicidad de esferas de la realidad, la permeabilidad de sus fronteras, y la activa interacción entre todos los seres que las habitan.

La supervivencia de los seres humanos depende en gran medida de guardar un equilibrio armonioso entre los habitantes de estos diferentes mundos.

(Sobrevilla, D: 2007) manifiesta que habitualmente se habla de la cultura peruana como si se tratara de una sola cultura, más o menos unificada luego de un proceso de mestizaje. Sin embargo, el Perú es un país multicultural. Lo fue ya en la época precolombina, cuando los incas impusieron su dominación a numerosas culturas a partir de la expansión de Pachacutec y también lo siguió siendo con la llegada de los españoles, cuya cultura pasó entonces a ser hegemónica, desplazando a la incaica que se convirtió en una cultura subalterna.

\section{FILOSOFÍA EN LA CONCEPCIÓN INTERCULTURAL}

(Estermann, J: 1998) señala que la filosofía intercultural, surgida a comienzos de la década de los noventa, no se entiende como una corriente entre otras, sino ante todo como una cierta manera de hacer filosofía.

Su tema principal es la interculturalidad, esta relación sui generis entre las distintas culturas.

Por lo tanto, no pretende reemplazar a las filosofías contextuales e inculturadas con una filosofía supra-cultural, sino articularlas de una manera noreduccionista, ni hegemónica.

La filosofía intercultural ha surgido sobre todo en base a dos experiencias fundamentales: 
1. La conciencia creciente de la condicionalidad cultural (culturocentrismo) de la tradición dominante de la filosofía occidental.

2. Las tendencias actuales -en sí contradictorias- del proceso acelerado de la globalización cultural por medio de una supercultura económica y postmoderna por un lado, y el incremento de conflictos y guerras por razones étnicas y culturales por otro lado.

También quisiéramos señalar que una importante corriente dentro de la filosofía intercultural apunta a que, más que comunicación, es necesaria una comunión señala que en la interculturalidad se produce un conflicto entre cosmologías, que se entendería como:

1. Una visión del mundo más o menos racional y coherente, y sería también

2. Lo que se siente pero no se puede describir.

Es decir, la doble dimensión racionalintuitiva como elementos filosóficamente válidos para el conocimiento se presenta en esta doble definición de lo que entendemos por cosmología.

Estermann considera que toda cultura tiene tres dimensiones: la dimensión lógica, la mítico-simbólica y la mistérica. La dimensión lógica corresponde a todo aquello que puede ser pensado por una cultura. La dimensión mítico-simbólica es aquello que puede ser creído pero no es pensado ni definido. La dimensión mistérica es aquello que no puede ser pensado ni definido y que supera toda conceptualización y simbolización.

Es justamente en esta dinámica, sobre todo en las dos últimas dimensiones donde podemos comprender mejor a la etnia cocama y en general a todas las demás etnias amazónicas. Existen muchos acontecimientos en la vida de la comunidad que corroboran este hecho desde las actividades más simples como puede ser la representación de ciertos aspectos artísticos y teatrales hasta aspectos que tienen que ver con la propia supervivencia, más relacionadas con la economía: la caza, la pesca y recolección. Ellos "saben" no de manera racional, al puro estilo europeo, sino por los "signos de la naturaleza" cuando deben pescar, cazar animales de la selva y recoger productos como la miel de abeja que ayudarán a la supervivencia diaria del grupo.

Una vez constatada esta aportación, como nos situamos en el ámbito de la comunicación, no entraremos en lo que no es pensable. Pero en este punto debemos hacer otra puntualización y señalar que entre lo pensado y lo decible puede haber otro desfase. No todo lo pensable es decible. No todo lo decible es expresable. Hay que aceptar que la incomunicación forma parte también de la comunicación. En este punto los códigos de expresión emotiva de algunas culturas son determinantes a la hora de condicionar las manifestaciones emotivas. Por ejemplo, existen culturas, como la japonesa, que son actitudinalmente expresivas y que dicen más con sus gestos que con sus palabras y hasta les puede chocar enormemente la reiterada expresión verbal de sentimientos como el amor. La forma de expresar el amor para ellos, no es tan verbal sino más bien actitudinal.

La filosofía intercultural critica la pretensión absolutista y universalista de la filosofía occidental como un caso de ideologización. Una determinada concepción del mundo surgida en una 
cultura particular, es concebida y definida como la concepción universalmente válida y verdadera.

El afán súper o supra cultural de la filosofía occidental en lo teórico se convierte en imperialismo y hegemonismo económico y político en lo práctico. En la modernidad, se da la ecuación de que el proceso de desarrollo y progreso es idéntico al proceso de occidentalización.

En la filosofía de América Latina, este cortocircuito intelectual se nota muy claramente: Hasta la segunda mitad de este siglo, un filósofo latinoamericano era considerado verdaderamente "filósofo" en la medida en que era capaz de occidentalizarse, es decir, de imitar las corrientes y posturas vigentes en Occidente.

Al respecto, José Carlos Mariátegui (1925) escribió: "Todos los pensadores de nuestra América se han educado en una escuela europea. No se siente en su obra el espíritu de la raza. La producción intelectual del continente carece de rasgos propios. No tiene contornos originales. El pensamiento hispanoamericano no es generalmente sino una rapsodia compuesta con motivos y elementos del pensamiento europeo".

Otros pensadores continuaron la crítica Mariateguista acuñando para esta condición términos propios, como por ejemplo, Víctor Andrés Belaunde acuñó para esta condición típica de la filosofía latinoamericana el término "anatopismo" y Augusto Salazar Bondy habla de una profunda "inautenticidad" y "alienación"; por su parte Leopoldo Zea habla de "servidumbre" y "dependencia" y Enrique Dussel la llama "ontología del centro". Es decir, las tendencias de la filosofía latinoamericana se han basado en moldes europeos dentro de la cual teníamos que encajar nuestra diferente realidad, justamente los autores arriba mencionados hacen la crítica a esta tendencia, porque van tomando conciencia que estos tipos de filosofía responden más bien a una "filosofía de la dominación", de la cual hay que sustraerse poco a poco para llegar al nacimiento de la propia filosofía latinoamericana que responda, sirva y represente a esta realidad tan diferente y distante de la europea.

(Almudena, H. 2002:9) sostiene básicamente, que los seres humanos "construyen" la realidad en la que viven a través de una selección de los fenómenos que contemplan. Esta selección se realiza a través de dos mecanismos básicos:

1. El modo en que los grupos humanos "ordenan" esa realidad a través de los parámetros tiempo y espacio.

2. El modo en que "representan" esa realidad, bien a través de signos que están contenidos en ella, lo que da lugar a los mitos, o que son arbitrarios y distintos de la realidad que representan, lo que da lugar a la abstracción de la ciencia.

Continúa Almudena señalando que, la percepción que tenemos de la realidad dependerá del modo de representación que utilicemos para "construir" el tiempo y el espacio; a su vez, que dependiendo de si la representación es metonímica o metafórica, el peso del espacio o del tiempo será priorizado de distinta manera, resultando en la construcción social de realidades más estáticas o más dinámicas y de identidades más relacionales o mas individualizadas, lo que cobra sentido en la mutua interrelación con la complejidad socioeconómica de cada grupo humano, 
pues la identidad debe comprenderse como el mecanismo por el cual los seres humanos se hacen una idea de la realidad y de su posición en ella que les permita sobrevivir eficazmente con unas condiciones materiales dadas. En este sentido, los mecanismos de identidad constituyen un instrumento cognitivo esencial para que los seres humanos sientan suficiente control sobre sus circunstancias de vida, por lo que su modelación dependerá del control material real que sobre ellas tengan. La identidad se construye conforme a una serie de relaciones estructurales como son:

-Identidad relacional

-Metonimia como modo de representación

-Escaso control material de la realidad

-Resistencia al cambio (se valora como riesgo)

-Espacio como eje prioritario de ordenación de la realidad

Almudena cree además, que sobre estas relaciones estructurales se desarrollan particularidades personales o culturales, es decir, que las sociedades pueden transformarse siguiendo ritmos y direcciones distintas a pesar de que el cambio no ha sido deseado por las culturas, generándose un proceso de complejidad en la relación material con la realidad.

Gevaert, J. (2003:150) sostiene que el conocimiento humano no se encuentra nunca en estado puro, es decir, separado de la voluntad, de los valores, de los sentimientos, del afecto, de las necesidades vitales ni de las actividades humanas. El conocimiento es un aspecto y una modalidad de la interacción humana con la realidad y determina en gran medida su carácter "humano"

Este carácter integral del conocimiento es lo que posibilita diferentes maneras de relacionarse con la naturaleza y las demás personas y de entenderlas desde diversos puntos de vista -pensamiento divergente- (Ver Edward De Bono), sin que esto signifique una contradicción con la verdad, lo que pasa es que la misma limitación cognitiva del hombre en el sentido que no podemos captar toda la realidad tal como es, nos lleva solamente a visualizar aspectos momentáneos, como instantáneas fotográficas, en una realidad que fluye constantemente al más puro estilo Heracliteano y que cambia en una dinámica que ni siquiera podemos imaginar, entonces en este sentido, de por sí ya nos encontramos frente a una desventaja natural, que puede ser mínimamente contrapesada por una forma o estilo de pensamiento holístico, sistémico e integrador, es decir complejo, que nos abra a la dinámica del conocimiento continuo, solamente en este cambio de actitud posibilitaremos un cambio de "aptitud" que nos llevará a la posibilidad de conocer otras racionalidades en un mundo cada vez más cambiante y complejo.

\section{CONCLUSIONES:}

Existe una nueva valoración acerca de las formas culturales de los pueblos andinos y amazónicos por los cuales también valoramos sus formas de pensamiento y racionalidad como parte de su cultura.

Estas valoraciones son positivas en cuanto nos permite romper con paradigmas etnocentristas que solo refuerzan una forma de pensamiento único centrado en formas ideológicas cerradas y dogmáticas, que no han hecho más que llevar al hombre a formas totalitarias y opuestas que casi siempre han terminado en confrontaciones bélicas, no nos olvidemos que la 
primera y segunda guerra mundial han obedecido a este tipo de pensamiento y probablemente si se diera la tercera guerra mundial, sería por que no se ha superado este tipo de pensamiento único, dogmático y excluyente, es lo que acontece actualmente con Corea del Norte y con el problema árabe-israelí.

La posibilidad de vivir en paz respetando la otredad, consiste en la apertura a nuevas realidades culturales, distintas a las nuestras que nos llevará a un conocimiento profundo de aspectos que no hemos considerado y reflexionado, esta apertura se encuentra representada por un paradigma sistémico y complejo que considera a la realidad humana y social como un todo integral y holístico que hay que ampliar en todos los aspectos, al respecto la tarea está abierta y pendiente.

\section{REFERENCIAS:}

AIDESEP/ISPP (2009) Visiones Kukama-Kukamiria en relación al bosque y la sociedad. Iquitos: Programa de Formación de Maestros Bilingües de la Amazonía Peruana (FORMABIAP).

ALMUDENA, H. (2002) Arqueología de la Identidad. Madrid: Ediciones Akal.

ARDITO VEGA, W. (1993) Las reducciones Jesuitas de Maynas. Lima: Ediciones CAAAP.

BERENGUER CASTELLARY (Comp.) (1984) Sobre el concepto de cultura. Barcelona: Editorial Mitre.

EL OJO VERDE. Cosmovisiones Amazónicas y Familias Linguísticas. FORMABIAP, Iquitos.

ESPINOSA, L. (1989) Breve diccionario analítico castellano-tupi del Perú sección Cocama. Iquitos: Ediciones CETA.
ESTERMANN, J. (1998) Filosofía Andina, estudio intercultural de la sabiduría autóctona andina. Cusco: Ediciones Abya-Yala.

GARCÍA RIVERA, F. (2007) Fonologías Volumen I, serie Descripciones Linguisticas. Iquitos: FORMABIAP.

GEVAERT, J. (2003) El problema del hombre: Introducción a la Antropología Filosófica. Salamanca: Ediciones Sígueme.

HELBERG CHÁVEZ, H. (2001) Fundamentación Intercultural del Conocimiento. Lima: Programa FORTEPE.

HELBERG CHÁVEZ, H. (2001) Pedagogía de la Interculturalidad. Lima: Programa FORTE-PE.

ORTIZ RESCANIERE, A. (2006) Mitologías Amerindias. Madrid: Editorial Trotta.

ROMERO, P. (2003) Paradigma de la Complejidad, modelos científicos y conocimiento educativo. En http:// www3.usal.es/teoriaeducacion

ROSTWOROWSKI, M. (2007) Estructuras andinas del poder: Ideología religiosa y política. Lima: Instituto de Estudios Peruanos (IEP).

SOBREVILLA, D. Introducción a la Filosofía de la cultura y al Estudio de las Culturas en el Perú.

SUNCIÓN HERNÁNDEZ, V. (2010) Antecedentes etnohistóricos de la fundación de Requena. Iquitos: Ediciones Instituto de Investigaciones Educativas e Históricas de la Amazonía Peruana. 